\title{
Migraine in the era of precision medicine
}

\author{
Lv-Ming Zhang ${ }^{1}$, Zhao Dong ${ }^{2 *}$, Sheng-Yuan Yu ${ }^{2 *}$ \\ ${ }^{1}$ Department of Neurology, Aerospace Center Hospital/Aerospace Clinical Medical College Affiliated to Peking University, Beijing 100049, China; \\ ${ }^{2}$ Department of Neurology, Chinese PLA General Hospital, Beijing 100853, China \\ Contributions: (I) Conception and design: Z Dong, SY Yu; (II) Administrative support: None; (III) Provision of study materials or patients: None; \\ (IV) Collection and assembly of data: None; (V) Data analysis and interpretation: None; (VI) Manuscript writing: All authors; (VII) Final approval of \\ manuscript: All authors. \\ *These authors contributed equally to this work. \\ Correspondence to: Prof. Zhao Dong. Department of Neurology, Chinese PLA General Hospital, Fuxing Road 28, Haidian District, Beijing 100853, \\ China. Email: dong_zhaozhao@126.com; Prof. Shengyuan Yu. Department of Neurology, Chinese PLA General Hospital, Fuxing Road 28, Haidian \\ District, Beijing 100853, China. Email: yusy1963@126.com.
}

\begin{abstract}
Migraine is a common neurovascular disorder in the neurologic clinics whose mechanisms have been explored for several years. The aura has been considered to be attributed to cortical spreading depression (CSD) and dysfunction of the trigeminovascular system is the key factor that has been considered in the pathogenesis of migraine pain. Moreover, three genes (CACNA1A, ATP1A2, and SCN1A) have come from studies performed in individuals with familial hemiplegic migraine (FHM), a monogenic form of migraine with aura. Therapies targeting on the neuropeptids and genes may be helpful in the precision medicine of migraineurs. 5-hydroxytryptamine (5-HT) receptor agonists and calcitonin gene-related peptide (CGRP) receptor antagonists have demonstrated efficacy in the acute specific treatment of migraine attacks. Therefore, ongoing and future efforts to find new vulnerabilities of migraine, unravel the complexity of drug therapy, and perform biomarker-driven clinical trials are necessary to improve outcomes for patients with migraine.
\end{abstract}

Keywords: Migraine; precision medicine; neuropeptides; genes

Submitted Feb 14, 2016. Accepted for publication Mar 09, 2016.

doi: 10.21037/atm.2016.03.13

View this article at: http://dx.doi.org/10.21037/atm.2016.03.13

\section{Introduction}

Migraine is a common neurovascular disorder which is characterized by attacks of moderate to severe headaches lasting from 4 to 72 hours, often unilateral and pulsating, and associated with nausea, vomiting, photophobia and phonophobia (1). Migraine has been ranked as the 6th disabling condition by World Health Organization (WHO) (2), with a domestic prevalence of $9.3 \%$ (3) and the global prevalence of around $10 \%$ (4). Patients with migraine are generally aged from 25 to 50 , and the risk of migraine in females is three times higher than that in males $(5,6)$. Migraine has become a significant impact on the quality of people's lives, as well as a major economic and societal burden $(3,7,8)$.

The mechanisms of migraine have been explored for several years and the most accepted opinion is that a combination of both vascular and neural mechanisms is involved in the initiation and perpetuation of migraine $(9,10)$. Primarily the generation of migraine pain is attributed to activation of the trigeminovascular system. The aura has been considered to be attributed to cortical spreading depression (CSD) (11). However, the pathogenesis of migraine is not clear enough. Therefore, recent studies have devoted the genetic susceptibility research which may also be a neurobiological factor in the etiology of this disorder (12-14). Familial hemiplegic migraine (FHM), an autosomal dominant migraine with special aura, has been identified mutations in three causal genes (15). Functional studies in cellular and animal models of mutant alleles provide direct evidence for neuronal hyperexcitability as one cellular mechanism underlying headache or aura in 
FHM (16). While genome wide association studies (GWAS) have also shed new light on the types of genes involved in common migraine susceptibility, many candidate gene association studies have focused on neurotransmitter related pathways. Therefore, genes affecting synthesis and activity of neurotransmitters are potential candidates for involvement in migraine susceptibility. With the rapid development of genetics, the treatment of diseases has entered the era of precision medicine.

\section{Precision medicine}

As early as in 2004, the discovery of epidermal growth factor receptor (EGFR) provided a theoretical basis for targeted therapy of lung cancer (17). However, it did not get a further description until a paper occurrence in 2012 in The New England Journal of Medicine-coupling established clinicalpathological indexes with state-of-the-art molecular profiling to create diagnostic, prognostic, and therapeutic strategies precisely tailored to each patient's requirements (18). From then on, the term precision medicine was used to describe accurate medical treatments according to each patient's molecular data, genomics, and systems biology. When we talk about the precision medicine, we have to mention the term "Personalized Medicine". Precision medicine is similar to but always much more than personalized medicine. Personalized medicine refers to determining specific information about a patient and then prescribing a treatment that is specific for that patient. Personalized medicine involves defining disease subtypes and defining biomarkers that can identify which patients who are most likely to benefit from a specific treatment (19). It is just the addition of data mining to improved genomic analyses leading to the new term "precision medicine" (20).

Therefore, a greater understanding of the pathogenesis of migraine will be helpful to leading to identification of clinically relevant biomarkers, possibly actionable genetic mutations, and then getting an ideal treatment.

\section{The pathogenesis of migraine}

Migraine is viewed as a neurovascular disease caused by a primary brain dysfunction, leading to activation of the trigeminovascular system and the release of vasoactive neuropeptides. CSD originating in the occipital region is thought to represent the neurobiological underpinning of visual aura (21).

\section{Cortical spreading depression (CSD)}

CSD is a self-propagating wave of neuronal and glial depolarization (22), which is identified as the reason of the neurological aura symptoms (23). CSD is initiated by massive increases in extracellular potassium ion concentration and excitatory glutamate. The biochemical changes can trigger the activations of meningeal trigeminal endings and trigeminovascular system, causing the headache phase. CSD can also cause regional cerebral blood flow decreased in the cortex (24).

\section{The trigeminovascular system}

The activation of trigeminovascular system is the widely accepted theory of migraine headache. This system consists of pseudo-unipolar neurons in the trigeminal ganglion with primary afferents innervating the pial and dural meningeal vessels surrounding the brain and efferent projections synapsing with second order neurons in the trigeminal nucleus caudalis (TNC) (25) which is also called trigeminocervical complex (TCC) that extends from the dorsal medulla to the dorsal spinal horn of the first two cervical segments. The second-order neurons of the TCC project to the posterior thalamus (26).

The pain during a migraine attack is associated with the release of the CGRP which has a key role in migraine pathophysiology. CGRP is a 37 amino acid neuropeptide belongs in the calciton in gene peptide super family. Activation of trigeminal nociceptive terminals will stimulate the release of CGRP, which can increase the sensitivity of perivascular nociceptors and dilate cranial vessels. Clinical studies have fully established the importance of CGRP in migraine pathogenesis (27-29). CGRP levels have been reported to be elevated during spontaneous and nitroglycerine-induced migraine and reduced coincident with pain relief. Intravenous injection of CGRP caused delayed headaches, which for some subjects met the criteria for induced migraine $(30,31)$. Notably, the delayed onset of migraine-like headaches was seen only in migraineurs. Nonmigraineurs experienced only an initial mild headache or fullness-of-head sensation. This suggests that migraineurs are unusually sensitive to CGRP actions.

Another neuronal messenger molecule that has been suggested to have an important role in migraine pathophysiology is pituitary adenylate cyclase-activating polypeptide (PACAP). PACAP is encoded by ADCYAP1 gene, 
which expresses two forms containing either 27 or 38 amino acids with PACAP-38 representing $90 \%$ of PACAP forms in mammalian tissues (32). In the trigeminovascular system, PACAP is expressed in the spinal cord, trigeminal ganglia, and TNC (33). Intravenous injection of PACAP induces migraine-like symptoms and dilation of the middle meningeal artery (MMA) in both healthy and migraine patients. Migraineurs had elevated levels of PACAP peptide during the ictal phase relative to the interictal phase (34).

\section{Genomic analyses for migraine}

Identifying genes for multifactorial disorders like migraine is difficult because multiple genes are always with low penetrance, contributing to susceptibility of the disorder (35). Moreover, the resulting phenotype is influenced by both endogenous and exogenous non-genetic factors. Specifically, FHM is a rare monogenic migraine. Besides the FHM, genetics work also has been done to explore the mechanism of other migraine generation including exploring the fields of neuropeptides, hormonal related genes and so on. Although much effort has been done to explore the genetics of migraine, there are only few outcomes.

\section{FHM related genes}

There are three causative genes have been described in FHM: $C A C N A 1 A$ on chromosome19p13 (FHM1) (36), ATP1A2 at 1q23 (FHM2) (37), and SCN1A at 2q24 (FHM3) (38). The $C A C N A 1 A$ gene encodes the $\alpha 1 \mathrm{~A}$ subunit of the $\mathrm{P} / \mathrm{Q}$ type neuronal calcium channel (39) presenting with FHM1 (40). FHM1 mutations produce gain-of-function of the $\mathrm{Ca}(\mathrm{V}) 2.1$ channel and as a consequence, increased $\mathrm{Ca}$ (V) 2.1-dependent neurotransmitter release from cortical neurons and facilitation of in vivo induction and propagation of CSD (41). ATP1A2, encodes the $\alpha 2$ subunit of the $\mathrm{Na}+\mathrm{K}+$ ATPase, is expressed in astrocytes and involved in the clearance of extracellular $\mathrm{K}+$ and production of a $\mathrm{Na}+$ gradient used in the reuptake of glutamate. $S C N 1 A$ encodes the $\alpha 1$ subunit of the neuronal voltage gated sodium channel Nav1.1. This channel is critical in the generation and propagation of action potentials (42). SCN1A gene mutation leads to accelerated channel recovery from fast inactivation which increases dendrite excitability and neuronal firing. Mutations in ion channels could have led towards the vasogenic path but the consequent elevated extracellular glutamate and $\mathrm{K}^{+}$levels support neurogenic theory leading to reduced CSD threshold in migraine (43).
In 2012, mutations in the proline-rich transmembrane protein 2 gene (PRRT2) have been shown to be associated with hemiplegic migraine (44). PRRT2 codes for a transmembrane protein, which has an unknown function that is capable to bind to synaptosomal-associated protein 25 (SNAP25), suggesting a role in synaptic exocytosis (45). Mutations in the SLC4A4 gene (46) and SLC1A4 gene (47) have also been reported in the FHM, although these four mutations are relatively rare or even "private".

\section{Hormonal related genes}

Clinical and epidemiological observations indicate a strong correlation between female gender, sex female hormones, and migraine susceptibility. For these years, some genes have been verified participate the menstrual migraine (MM) generation.

The polymorphic estrogen receptor 1 (ESR1) gene at human chromosome 6q25.1 has eight exons and seven introns and spans about $300 \mathrm{~kb}$ in length (48). A metaanalysis in 2015 get a conclusion that exon $4325 \mathrm{C}>\mathrm{G}$ and exon $8594 \mathrm{G}>\mathrm{A}$ polymorphisms of the ESR1 gene conferred increased susceptibility to migraine, basing on data from molecular and epidemiological studies (49). At the same time ESR1is expressed in many areas of the brain regulating many functions including regulating gene expression through cell signaling affecting glutamate and serotonin synthesis and CGRP and can regulate vascular tone by stimulating release of nitric oxide $(\mathrm{NO})(50,51)$. Progesterone receptor gene $(P G R)$, located on chromosome 11q22 (OMIM\# 607311), encodes a steroid receptor that principally mediates the effect of progesterone on the establishment and maintenance of reproductive events (UniProt\# P06401). PROGINS PGR polymorphism does not directly predispose to migraine but significantly delays migraine onset probably via a reduction in brain neuronal excitability (52).

\section{Migraine related neurologic syndrome}

Migraine has been reported as clinical manifestations in several genetic vasculopathies. Cerebral autosomal dominant arteriopathy with subcortical infarcts and leukoencephalopathy (CADASIL) is a monogenic-inherited form systemic vasculopathy linked to mutations in the Notch 3 gene (located on chromosome 19p13.2-p13.1), which encodes a cell surface receptor (53). The incidence of migraine with aura in CADASIL is five times greater 
compared with the general population $(54,55)$.

The other one is retinal vasculopathy with cerebral leukodystrophy (RVCL) which is a neurovascular syndrome characterized by vascular retinopathy, cognitive impairment, depression, migraine (mainly without aura), focal neurologic symptoms and intracerebral mass lesions. The TREX1 gene has just been reported independently, and it is still unclear how the carboxyl truncating mutations in TREX1 lead to the phenotype or pathogenesis of RVCL (56).

COL $4 A 1$ related-syndromes is caused by COL $4 A 1$ mutations which will cause neurological symptoms including hemiparesis, seizures, visual loss, dystonia, stroke, mental retardation, cognitive impairment and dementia. The association of COLA4A1 mutations with migraine is not entirely certain. To date, migraine with aura has been described only in one family with COLA4A1 mutation (57).

Two families with migraine with aura and familial anticipated sleep phase syndrome (FASPS) have been screened with a mutation in the circadian Period2 (PER2) gene, within the casein kinase 1 (CK1)-binding domain of the Per2 protein. Mice carrying the CK1 $\delta$ T44 mutation have a reduced threshold for CSD after exposure of the cortical surface to $1 \mathrm{uM}$ potassium chloride and increased spontaneous and evoked calcium activity in astrocytes (58).

\section{Neuropeptides related genes}

Receptor activity modifying protein 1 (RAMP1) is known to be a key receptor subunit of CGRP, which functions as an important neural transmitter in migraine (59). The changes in the expression of RAMP1 can affect the sensitivity of cell to CGRP (60). The over-expressed human RAMP1Nestin/ $R A M P 1$ transgenic mice, can mimic photophobia and allodynia just like migraine, when intracerebral ventricular administration of CGRP $(61,62)$. However, genetic polymorphism studies failed to link migraine with variations in $R A M P 1$ gene $(63,64)$. A few attempts are to investigate the relationship between deoxyribonucleic acid (DNA) methylation of $R A M P 1$ gene and migraine. Recently a study provides that DNA methylation at $R A M P 1$ promoter might play a role in migraine. A lower methlytion level at $(+89,+94,+96)$ $\mathrm{CpG}$ unit may be a risk of migraine in females (65).

As a potent vasodilator implicated in migraine, $\mathrm{NO}$ has a strong correlation with CGRP. NO synthase 3 (NOS3) by expressing enzyme NOS regulates endothelial derived NO. The NOS3 gene is located on chromosome 7 and consists of 26 exons. The NOS 3 gene has numerous poly-morphisms which among them the Glu298Asp at exon 7 is the only single nucleotide polymorphism (SNP) (guanine to thymine at position 894) which leads to amino acid substitution (from glutamic acid to aspartic acid at position 298). Study has verified that migraine attacks after use of tricyclic antidepressants (TCAs) was significantly decreased in all genotypes of NOS3. Use of TCAs had no significant effect in intensity of headache in migraine patients, but by decreasing frequency of migraine attacks had an inhibitory role in migraine generation, particularly in patients with TT genotype (66).

\section{Others}

Recent studies have highlighted the role that the potassium channel, subfamily K, TWIK-related spinal cord K+ channel (TRESK) gene may play in migraine with aura. A main physiological function of TRESK is the modulation of nociception. Down-regulation of TRESK expression by siRNA increased the sensitivity to painful stimuli (67). Overexpression of TRESK in DRG neurons attenuates nerve injury-induced mechanical allodynia (68). The TRESK channel presents perhaps the best opportunity for development of antimigraine therapeutics, given its predicted role in controlling neuronal excitability (69).

The methylenetetrahydrofolate reductase (MTHFR) gene has been verified to increase the risk of ischemic stroke in migraine with aura (70). The gene encodes MTHFR enzyme that converts 5, 10-methylenetetrahydrofolate into 5-methylenetetrahydrofolate, which is the circulating form of folate in plasma. Folate is needed for conversion of homocysteine to methionine (71). In the presence of either homozygous or heterozygous C677T or A1298C variants of the MTHFR gene, the activity of the enzyme is downregulated, therefore homocysteine level in blood plasma increases (72). The decreased activity of the MTHFR enzyme is considered an important risk factor for migraine.

Transient receptor potential (TRP) channels are expressed in dural afferents including those containing CGRP. Activation of TRP channels promotes excitation of nociceptive afferent fibers and potentially leads to pain. In addition to pain, allodynia to mechanical and cold stimuli can result from sensitization of both peripheral afferents and of central pain pathways. In the TRP family, TRPV1 is highly expressed on peripheral nociceptors (73).

The relation of angiotensin-converting enzyme (ACE) and migraine is not clear. Recent studies showed the ACE D/D genotype have a synergistic effect with the MTHFR T/T genotype toward developing migraine (74). 
The dopaminergic system and glutamate also play major roles in migraine. Skorobogatykh et al. did a research about dopamine beta hydroxylase (DBH) polymorphisms rs1611115 and showed that the T-allele carriers (46.9\%) as compared to the CC genotype patients (53.1\%) have more severe migraine (75). TT genotype of rs2049046 in brain-derived neurotrophic factor $(B D N F)$ gene appears to influence susceptibility to migraine chronification. This polymorphism could also be a link for comorbidity of chronic migraine and mood disorders (76).

\section{Precision treatment for migraine}

Lots of studies have been done to explore the initiation, propagation, pathogenesis, and genetics of migraine. However, the ultimate aim is to get an excellent option to deal with migraine. We have reviewed the different pathogenesis of migraine including 5-HT, NO, CGRP, $\mathrm{PACAP}$ and other related neuropeptids. Hence, one strategy to abort migraine is to block the release of neuropeptides or their receptor activation. Abortive agents in acute migraine management exert a modulatory effect on the levels of circulating neuropeptides. Some of the material's receptors, agonist have been researched even used in the treatment.

\section{5-HT receptor agonist}

$5-\mathrm{HT} 1 \mathrm{~B} / 1 \mathrm{D}$ receptor agonists have a long history in the treatment of migraine. Ergot is the oldest medicine used as the antimigraine drug. Methysergide, a $5-\mathrm{HT}_{2 \mathrm{~B}}$ receptor antagonist, and ergotamine, a $5-\mathrm{HT}_{1 \mathrm{~A} / 1 \mathrm{~B} / 1 \mathrm{D} / 1 \mathrm{~F} / 2 \mathrm{~A} / 2 \mathrm{~B}}$ agonist, in migraine treatment spurred the early research at a pharmacological level (77). However, the side effects such as gangrene of the limbs due to a potent and long lasting vasoconstriction limited its popularization. After that, the triptans were demonstrated can induce downregulation in TNC activity (78) and decreased the enhanced neuronal firing in the brain stem in animal models (79). Sumatriptan, the first triptan as an agonist at $5-\mathrm{HT}_{1 \mathrm{~B} / \mathrm{D}}$ receptor (80), is verified effective and well-tolerated in patients (81). However, the agonist also has a peripheral vasoconstriction because of the presence of some $5-\mathrm{HT}_{1 \mathrm{~B}}$ receptors on coronary arteries, so sumatriptan is contraindicated in patients with cardiovascular disease (82). But it still has been proven to be effective and well-tolerated when used properly. In addition, sumatriptan stimulates $5-\mathrm{HT}_{1 \mathrm{D}}$ receptors located in trigeminal fiber endings, which inhibits the release of neuropeptides (83). As the first generation of triptans, sumatriptan has a low oral bioavailability (14\%), and a short half-life period of about 2 hours (84). The second generation triptans including zolmitriptan, naratriptan, rizatriptan, frovatriptan, almotriptan and eletriptan have a greater bioavailability, longer plasma halflife, and higher lipophilicity (85). Evidence-based medicine has indicated that the triptans are of level A for the acute treatment of migraine headache (85). The use of pure $5-\mathrm{HT}_{1 \mathrm{~F}}$ agonists is hypothesized could be effective as antimigraine abortive treatment due to higher receptor selectivity (26). However, recently clinical studies about $5-\mathrm{HT}_{1 \mathrm{~F}}$ receptor agonist, lasmiditan, revealed a high rate of central nervous system side effects in clinical trials included dizziness (often classified as severe), paresthesia, fatigue and vertigo $(86,87)$. Novel antimigraine drugs without peripheral vasoconstrictor side effects are still needed; compounds binding specifically to $5-\mathrm{HT}_{1 \mathrm{D}}, 5-\mathrm{HT}_{1 \mathrm{~F}}$ and $5-\mathrm{HT}_{7}$ receptors have been or are currently being investigated.

\section{CGRP receptor and monoclonal antibodies}

CGRP receptor antagonists have been developed as novel antimigraine drugs and found to be effective in the treatment of acute migraine attacks. Olcegepant (BIBN4096BS) is the first discovered selective CGRP-RAs (88). A multicenter, double blind, randomized (126 patients with migraine), clinical proof-of-concept study revealed the effectiveness of olcegepant for the treatment of acute migraine attacks (89). However, the intravenously administration limited its wide clinical use. Telcagepant was developed as an orally available medicine instead. It proved effective as a migraine abortive agent, with efficacy for 2-hour pain and 2-hour pain freedom, sustained pain freedom for 2-24 hours and 2-48 hours (90-92) and toward the migraine accompanying symptoms (nausea, photo and phono-phobia). However, the study was abandoned (93-95) because of asymptomatic liver toxicity in some patients. Another orally CGRP receptor antagonist MK-3207, also showed hepatotoxicity in some cases and its development was thus discontinued (96). Monoclonal antibodies targeting CGRP (CGRP-mAbs) or its receptor appear more promising with no liver toxicity. Whereas the small-molecule CGRP-RAs were developed only for the acute treatment of episodic migraine, the antiCGRP mAbs were designed for the prophylaxis of frequent episodic and chronic migraine in severe cases. Because of the large size of the mAbs, they cannot be administered orally, but only subcutaneously or intravenously. The humanized mAbs LY2951742 (developed by Arteus Therapeutics), 
ALD403 (developed by Alder Biopharmaceuticals) and LBR-101 (developed by Labrys Biologics-TEVA) have been investigated against episodic migraine. The studies are still in clinical trials. Currently, the only anti-CGRP-R mAb AMG 334 (a compound developed by Amgen) has been undergoing the Phase II clinical studies of episodic and chronic migraine. The results are still not yet available (97).

Further, PACAP-induced MMA dilation was abolished by the ATP-Sensitive Potassium (KATP) channel blocker glibenclamide. These observations that PACAP dilates MMA via activation of vascular KATP channels may provide a potential therapeutic target of migraine (98).

\section{Genes targeting}

Specifically, genetic analysis could contribute to better treatment choices. Collectively these data indicate that SNP analysis of candidate genes can assist in the diagnosis of migraine, as well as opening up the possibility of gene therapy for this disorder (99).

Though we have known CACNA1A, ATP1A2, SCN1A and $P R R T 2$ genes play important roles in migraine, the gene targeting therapies related studies are very few. Loredana Leo et al had generated the first FHM2 knock-in mouse model carrying the human W887R mutation in the Atp1a2 orthologous gene (100). However, there is still no FHM related knock-out models or other genetic therapies reported.

Parthenolide, a bioactive compound contained in the antimigraine preparations from Tanacetum parthenium (also known as feverfew), has been very recently shown to act as a partialagonist at TRPA1 channels (101). Although TRP channels appear a promising target for migraine treatment, there are no other products of this class in current development in clinical trials.

The MTHFR gene mutation has been verified if the MTHFR enzyme activity is down-regulated, homocysteine level in blood plasma will increases. Therefore, supplementation with folic acid, vitamin $\mathrm{B}_{6}$, and vitamin $\mathrm{B}_{12}$ for the people with MTHFR gene variant will be helpful. The T/T individuals should receive higher doses (102). However, the efficiency of ACE inhibitor lisinopril (103) and angiotensin 1 receptor blocker olmesartanin migraine prophylaxis suggests a potential relation between the reninangiotensin system (RAS) and migraine.

\section{Conclusions}

Migraine is a common, disabling, and undertreated worldwide problem. The activation of the trigeminovascular system and the genomic anomaly has been verified playing important roles in the migraine. The antimigraine drugs such as 5 -HT receptors agonists, CGRP receptor and monoclonal antibodies even have been used in the clinical treatment. Though research efforts have been done but there are still not enough specific therapies to treat migraine. So more complete understanding of the molecular pathways involved and the relevant genomic profile of migraine will aid in the development of new anti-migraine drugs and treatments, and or enable those currently available to be better targeted to suit individuals. In the era of precision, the integration of genomic data, functional studies, and data from biomarker-driven clinical trials will shape molecular profiling of migraine in the near future. Ongoing and future efforts to find new vulnerabilities of migraine, unravel the complexity of drug therapy, and perform biomarker-driven clinical trials are necessary to improve outcomes for patients with migraine. The best way to move forward is with a multidisciplinary approach incorporating results from emerging biochemical, pharmacologic, genetic studies and imaging techniques in order to better understand and treat this debilitating disease.

\section{Acknowledgements}

None.

\section{Footnote}

Conflicts of Interest: The authors have no conflicts of interest to declare.

\section{References}

1. Headache Classification Committee of the International Headache Society. The International Classification of Headache Disorders, 3rd edition (beta version). Cephalalgia 2013;33:629-808.

2. Global Burden of Disease Study 2013 Collaborators. Global, regional, and national incidence, prevalence, and years lived with disability for 301 acute and chronic diseases and injuries in 188 countries, 1990-2013: a systematic analysis for the Global Burden of Disease Study 2013. Lancet 2015;386:743-800.

3. Yu S, Liu R, Zhao G, et al. The prevalence and burden of primary headaches in China: a population-based door-to- 
door survey. Headache 2012;52:582-91.

4. Jensen R, Stovner LJ. Epidemiology and comorbidity of headache. Lancet Neurol 2008;7:354-61.

5. Morotti M, Remorgida V, Venturini PL, et al. Progestinonly contraception compared with extended combined oral contraceptive in women with migraine without aura: a retrospective pilot study. Eur J Obstet Gynecol Reprod Biol 2014;183:178-82.

6. Tali D, Menahem I, Vered E, et al. Upper cervical mobility, posture and myofascial trigger points in subjects with episodic migraine: case-control study. J Bodyw Mov Ther 2014;18:569-75.

7. Wang Y, Zhou J, Fan X, et al. Classification and clinical features of headache patients: an outpatient clinic study from China. J Headache Pain 2011;12:561-7.

8. SStovner Lj, Hagen $\mathrm{K}$, Jensen $\mathrm{R}$, et al. The global burden of headache: a documentation of headache prevalence and disability worldwide. Cephalalgia 2007;27:193-210.

9. Amin FM, Asghar MS, Hougaard A, et al. Magnetic resonance angiography of intracranial and extracranial arteries in patients with spontaneous migraine without aura: a cross-sectional study. Lancet Neurol 2013;12:454-61.

10. Edvinsson L, Villalón CM, MaassenVanDenBrink A. Basic mechanisms of migraine and its acute treatment. Pharmacol Ther 2012;136:319-33.

11. Dalkara T, Zervas NT, Moskowitz MA. From spreading depression to the trigeminovascular system. Neurol Sci 2006;27 Suppl 2:S86-90.

12. Inchauspe CG, Pilati N, Di Guilmi MN, et al. Familial hemiplegic migraine type- 1 mutated cav2.1 calcium channels alter inhibitory and excitatory synaptic transmission in the lateral superior olive of mice. Hear Res 2015;319:56-68.

13. Güler S, Gürkan H, Tozkir H, et al. An investigation of the relationship between the eNOS gene polymorphism and diagnosed migraine. Balkan J Med Genet 2014;17:49-59.

14. Fawzi MS, El-Shal AS, Rashad NM, et al. Influence of tumor necrosis factor alpha gene promoter polymorphisms and its serum level on migraine susceptibility in Egyptian patients. J Neurol Sci 2015;348:74-80.

15. de Vries B, Frants RR, Ferrari MD, et al. Molecular genetics of migraine. Hum Genet 2009;126:115-32.

16. Garza-López E, Sandoval A, González-Ramírez R, et al. Familial hemiplegic migraine type 1 mutations W1684R and V1696I alter G protein-mediated regulation of $\mathrm{Ca}(\mathrm{V}) 2.1$ voltage-gated calcium channels. Biochim Biophys Acta 2012;1822:1238-46.

17. Lynch TJ, Bell DW, Sordella R, et al. Activating mutations in the epidermal growth factor receptor underlying responsiveness of non-small-cell lung cancer to gefitinib. N Engl J Med 2004;350:2129-39.

18. Mirnezami R, Nicholson J, Darzi A. Preparing for Precision Medicine. N Engl J Med 2012;366:489-91.

19. Klonoff DC. Personalized medicine for diabetes. J Diabetes Sci Technol 2008;2:335-41.

20. Klonoff DC. Precision Medicine for Managing Diabetes. J Diabetes Sci Technol 2015;9:3-7.

21. Pietrobon D, Striessnig J. Neurobiology of migraine. Nat Rev Neurosci 2003;4:386-98.

22. Somjen GG. Aristides Leão's discovery of cortical spreading depression. J Neurophysiol 2005;94:2-4.

23. Tfelt-Hansen PC. History of migraine with aura and cortical spreading depression from 1941 and onwards. Cephalalgia 2010;30:780-92.

24. Zhang X, Levy D, Noseda R, et al. Activation of eningeal nociceptors by cortical spreading depression: implications for migraine with aura. J Neurosci 2010;30:8807-14.

25. Liu Y, Broman J, Edvinsson L. Central projections of the sensory innervations of the rat middle meningeal artery. Brain Res 2008;1208:103-10.

26. Goadsby PJ, Lipton RB, Ferrari MD. Migraine current understanding and treatment. N Engl J Med 2002;346:257-70.

27. Ho TW, Edvinsson L, Goadsby PJ. CGRP and its receptors provide new insights into migraine pathophysiology. Nat Rev Neurol 2010;6:573-82.

28. Villalón CM, Olesen J. The role of CGRP in the pathophysiology of migraine and efficacy of CGRP receptor antagonists as acute antimigraine drugs. Pharmacol Ther 2009;124:309-23.

29. Russo AF. Calcitonin gene-related peptide (CGRP): a new target for migraine. Annu Rev Pharmacol Toxicol 2015;55:533-52.

30. Hansen JM, Hauge AW, Olesen J, et al. Calcitonin generelated peptide triggers migraine-like attacks in patients with migraine with aura. Cephalalgia 2010;30:1179-86.

31. Asghar MS, Hansen AE, Amin FM, et al. Evidence for a vascular factor in migraine. Ann Neurol 2011;69:635-45.

32. Bourgault S, Vaudry D, Botia B, et al. Novel stable PACAP analogs with potent activity towards the PAC1receptor. Peptides 2008;29:919-32.

33. Schytz HW, Olesen J, Ashina M. The PACAP receptor: a novel target for migraine treatment. Neurotherapeutics 2010;7:191-6.

34. Tuka B, Helyes Z, Markovics A, et al. Alterations in PACAP-38-like immunereactivity in the plasma 
during ictal and interictal periods of migraine patients. Cephalalgia 2013;33:1085-95.

35. Ferrari MD, Dichgans M. Genetics of primary headache. In: Silberstein SD, Lipton RB, Dodick DW, editors. Wolff's Headache and Other Head Pain, 8th ed. New York: Oxford University Press, 2007:133-49.

36. Ophoff RA, Terwindt GM, Vergouwe MN, et al. Familial hemiplegic migraine and episodic ataxia type- 2 are caused by mutations in the Ca2+ channel gene CACNL1A4. Cell 1996;87:543-52.

37. De Fusco M, Marconi R, Silvestri L, et al. Haploinsufficiency of ATP1A2 encoding the $\mathrm{Na}+\mathrm{K}+$ pump alpha2 subunit associated with familial hemiplegic migraine type 2. Nat Genet 2003;33:192-6.

38. Dichgans M, Freilinger T, Eckstein G, et al. Mutation in the neuronal voltage-gated sodium channel SCN1A in familial hemiplegic migraine. Lancet 2005;366:371-7.

39. Kim EY, Rumpf CH, Fujiwara $Y$, et al. Structures of $\mathrm{Ca}$ (V) $2 \mathrm{Ca}(2+) / \mathrm{CaM}-\mathrm{IQ}$ domain complexes reveal binding modes that underlie calcium-dependent inactivation and facilitation. Structure 2008;16:1455-67.

40. Pietrobon D. Familial hemiplegic migraine. Neurotherapeutics 2007;4:274-84.

41. Hadjikhani N, Sanchez Del Rio M, Wu O, et al. Mechanisms of migraine aura revealed by functional MRI in human visual cortex. Proc Natl Acad Sci U S A 2001;98:4687-92.

42. Wessman M, Terwindt GM, Kaunisto MA, et al. Migraine: a complex genetic disorder. Lancet Neurol 2007;6:521-32.

43. Moskowitz MA, Bolay H, Dalkara T. Deciphering migraine mechanisms: clues from familial hemiplegic migraine genotypes. Ann Neurol 2004;55:276-80.

44. Riant F, Roze E, Barbance C, et al. PRRT2 mutations cause hemiplegic migraine. Neurology 2012;79:2122-4.

45. Lee HY, Huang Y, Bruneau N, et al. Mutations in the novel protein PRRT2 cause paroxysmal kinesigenic dyskinesia with infantile convulsions. Cell Rep 2012;1:2-12.

46. Suzuki M, Van Paesschen W, Stalmans I, et al. Defective membrane expression of the $\mathrm{Na}+-\mathrm{HCO} 3$--cotrasporter NBCe1 is associated with familial migraine. Proc Natl Acad Sci USA 2010;107:15963-8.

47. Weir GA, Cader MZ. New directions in migraine. BMC Med 2011;9:116.

48. Cowley SM, Hoare S, Mosselman S, et al. Estrogen receptors alphaand beta form heterodimers on DNA. J Biol Chem 1997;272:19858-62.

49. Li L, Liu R, Dong Z, et al. Impact of ESR1 Gene Polymorphisms on Migraine Susceptibility: A Meta-
Analysis. Medicine (Baltimore) 2015;94:e0976.

50. Lewis DW, Winner P. The pharmacological treatment options for pediatric migraine: an evidence-based appraisal. NeuroRx 2006;3:181-91.

51. Gupta S, Mehrotra S, Villalon CM, et al. Potential role of female sex hormones in the pathophysiology of migraine. Pharmacol Ther 2007;113:321-40.

52. Palmirotta R, Barbanti P, Ialongo C, et al. Progesterone Receptor Gene (PROGINS) Polymorphism Correlates with Late Onset of Migraine. DNA Cell Biol 2015;34:208-12.

53. Chabriat H, Joutel A, Dichgans M, et al. CADASIL. Lancet Neurol 2009;8:643-53.

54. Nozari A, Dilekoz E, Sukhotinsky I, et al. Microemboli may link spreading depression, migraine aura, and patent foramen ovale. Ann Neurol 2010;67:221-9.

55. Vahedi K, Chabriat H, Levy C, et al. Migraine with aura and brain magnetic resonance imaging abnormalities in patients with CADASIL. Arch Neurol 2004;61:1237-40.

56. Richards A, van den Maagdenberg AM, Jen JC, et al. C-terminal truncations in human 3'-5' DNA exonuclease TREX1 cause autosomal dominant retinal vasculopathy with cerebral leukodystrophy. Nat Genet 2007;39:1068-70.

57. Breedveld G, de Coo IF, Lequin MH, et al. Novel mutations in three families confirm a major role of COL4A1 in hereditary porencephaly. J Med Genet 2006;43:490-5.

58. Silberstein SD, Dodick DV. Migraine genetics: Part II. Headache 2013;53:1218-29.

59. Kaiser EA, Russo AF. CGRP and migraine: could PACAP play a role too? Neuropeptides 2013;47:451-61.

60. Barwell J, Wootten D, Simms J, et al. RAMPs and CGRP receptors. Adv Exp Med Biol 2012;744:13-24.

61. Marquez de Prado B, Hammond DL, Russo AF. Genetic enhancement of calcitonin gene-related peptide-induced central sensitization to mechanical stimuli in mice. J Pain 2009;10:992-1000.

62. Recober A, Kaiser EA, Kuburas A, et al. Induction of multiple photophobic behaviors in a transgenic mouse sensitized to CGRP. Neuropharmacology 2010;58:156-65.

63. Sutherland HG, Buteri J, Menon S, et al. Association study of the calcitonin gene-related polypeptide-alpha (CALCA) and the receptor activity modifying 1 (RAMP1) genes with migraine. Gene 2013;515:187-92.

64. Rudkjobing LA, Esserlind AL, Olesen J. Future possibilities in migraine genetics. J Headache Pain 2012;13:505-11.

65. Wan DJ, Hou L, Zhang XF, et al. DNA methylation of RAMP1 gene in migraine: an exploratory analysis. J 
Headache Pain 2015;16:16:90.

66. Molana A, Mehrpour M, Vousooghi N, et al. Effect of NOS3 gene polymorphism on response to Tricyclic antidepressants in migraine attacks. Iran J Neurol 2014;13:154-9.

67. Zhou J, Yang CX, Zhong JY, et al. Intrathecal TRESK gene recombinant adenovirus attenuates spared nerve injury-induced neuropathic pain in rats. Neuroreport 2013;24:131-6.

68. Tulleuda A, Cokic B, Callejo G, et al. TRESK channel contribution to nociceptive sensory neurons excitability: modulation by nerve injury. Mol Pain 2011;7:30.

69. Dobler T, Springauf A, Tovornik S, et al. TRESK two-pore-domain $\mathrm{K}+$ channels constitute a significant component of background potassium currents in murine dorsal root ganglion neurones. J Physiol 2007;585:867-79.

70. Pezzini A, Grassi M, Del Zotto E, et al. Migraine Mediates the Influence of C677T MTHFR Genotypes on Ischemic Stroke Risk with a Stroke-Subtype Effect. Stroke 2007;38:3145-51.

71. Stuart S, Cox HC, Lea RA, et al. The Role of the MTHFR Gene in Migraine. Headache 2012;52:515-20.

72. Varga EA, Sturm AC, Misita CP, et al. Cardiology patient pages. Homocysteine and MTHFR mutations: relation to thrombosis and coronary artery disease. Circulation 2005;111:e289-93.

73. Caterina MJ, Julius D. The vanilloid receptor: A molecular gateway to the pain pathway. Annu Rev Neurosci 2001;24:487-517.

74. Lea RA, Ovcaric M, Sundholm J, et al. Genetic variants of angiotensin converting enzyme and methylenetetrahydrofolate reductase may act in combination to increase migraine susceptibility. Brain Res Mol Brain Res 2005;136:112-7.

75. Skorobogatykh K, Azimova J, Sergeev A, et al. EHMTI-0233. Clinical characteristics of migraine patients with dopaminergic gene polymorphisms RS1611115.J Headache Pain 2014;15:B35.

76. Azimova Y, Sergeev A, Skorobogatykh K. BDNF gene polymorphism RS2049046 in episodic and chronic migraine. J Headache Pain 2013;14:16.

77. Müller-Schweinitzer E, Weidmann H. Regional differences in the responsiveness of isolated arteries from cattle, dog and man. Agents Actions 1977;7:383-9.

78. Goadsby PJ, Knight Y. Inhibition of trigeminal neurones after intravenous administration of naratriptan through an action at 5-hydroxytryptamine (5-HT (1B/1D)) receptors. Br J Pharmacol 1997;122:918-22.
79. Lambert GA, Boers PM, Hoskin KL, et al. Suppression by eletriptan of the activation of trigeminovascular sensory neurons by glyceryl trinitrate. Brain Res 2002;953:181-8.

80. Hoyer D, Clarke DE, Fozard JR, et al. International Union of Pharmacology classification of receptors for 5-hydroxytryptamine (Serotonin). Pharmacol Rev 1994;46:157-203.

81. Ferrari MD, Saxena PR. Clinical and experimental effects of sumatriptan in humans. Trends Pharmacol Sci 1993;14:129-33.

82. MaassenVanDenBrink A, Reekers M, Bax WA, et al. Coronary side-effect potential of current and prospective antimigraine drugs. Circulation 1998;98:25-30.

83. Deleu D, Hanssens Y. Current and emerging secondgeneration triptans in acute migraine therapy: a comparative review. J Clin Pharmacol 2000;40:687-700.

84. Fowler PA, Lacey LF, Thomas M, et al. The clinical pharmacology, pharmacokinetics and metabolism of sumatriptan. Eur Neurol 1991;31:291-4.

85. Evers S, Afra J, Frese A, et al. EFNS guideline on the drug treatment of migraine -- revised report of an EFNS task force. Eur J Neurol 2009;16:968-81.

86. Ferrari MD, Farkkila M, Reuter U, et al. Acute treatment of migraine with the selective $5-\mathrm{HT} 1 \mathrm{~F}$ receptor agonist lasmiditan -- a randomized proof-of-concept trial. Cephalalgia 2010;30:1170-8.

87. Färkkilä M, Diener HC, Géraud G, et al. Efficacy and tolerability of lasmiditan, an oral 5-HT(1F) receptor agonist, for the acute treatment of migraine: a phase 2 randomised, placebo-controlled, parallel-group, doseranging study. Lancet Neurol 2012;11:405-13.

88. Doods H, Hallermayer G, Wu D, et al. Pharmacological profile of BIBN4096BS, the first selective small molecule CGRP antagonist. Br J Pharmacol 2000;129:420-3.

89. Olesen J, Diener HC, Husstedt IW, et al. Calcitonin gene-related peptide receptor antagonist BIBN 4096 BS for the acute treatment of migraine. N Engl J Med 2004;350:1104-10.

90. Connor KM, Shapiro RE, Diener HC, et al. Randomized, controlled trial of telcagepant for the acute treatment of migraine. Neurology 2009;73:970-7.

91. Ho TW, Ferrari MD, Dodick DW, et al. Efficacy and tolerability of MK-0974 (telcagepant), a new oral antagonist of calcitonin gene-related peptide receptor, compared with zolmitriptan for acute migraine: a randomised, placebo controlled, parallel-treatment trial. Lancet 2008;372:2115-23.

92. Ho TW, Mannix LK, Fan X, et al. Randomized controlled 
trial of an oral CGRP receptor antagonist, MK-0974, in acute treatment of migraine. Neurology 2008;70:1304-12.

93. Connor KM, Aurora SK, Loeys T, et al. Long-term tolerability of telcagepant for acute treatment of migraine in a randomized trial. Headache 2011;51:73-84.

94. Han TH, Blanchard RL, Palcza J, et al. Single- and multiple-dose pharmacokinetics and tolerability of telcagepant, an oral calcitonin gene related peptide receptor antagonist, in adults. J Clin Pharmacol 2010;50:1367-76.

95. Ho TW, Connor KM, Zhang Y, et al. Randomized controlled trial of the CGRP receptor antagonist telcagepant for migraine prevention. Neurology 2014;83:958-66.

96. Hewitt DJ, Aurora SK, Dodick DW, et al. Randomized controlled trial of the CGRP receptor antagonist MK3207 in the acute treatment of migraine. Cephalalgia 2011;31:712-22.

97. Mitsikostas DD, Alan M. Rapoport. New players in the preventive treatment of migraine. BMC Med 2015;13:279.

98. Syed AU, Koide M, May V, et al. Mechanism of Pituitary Adenylate Cyclase Activating Polypeptide (PACAP)Induced Dilation of Middle Meningeal Artery: Role of

Cite this article as: Zhang LM, Dong Z, Yu SY. Migraine in the era of precision medicine. Ann Transl Med 2016;4(6):105. doi: 10.21037/atm.2016.03.13
ATP-Sensitive Potassium (KATP) Channels. FASEB J 2013;27:877-9.

99. Bielinski SJ, Pankow JS, Li N, et al. ICAM-1 and VCAM1 polymorphisms, coronary artery calcium, and circulating levels of soluble ICAM-1: the multi-ethnic study of atherosclerosis (MESA). Atherosclerosis 2008;201:339-44.

100.Leo L, Gherardini L, Barone V, et al. Increased susceptibility to cortical spreading depression in the mouse model of familial hemiplegic migraine type 2. PLoS Genet 2011;7:e1002129.

101. Materazzi S, Benemei S, FusiC, et al. Parthenolide inhibits nociception and neurogenic vasodilatation in the trigeminovascular system by targeting the TRPA1 channel. Pain 2013;154:2750-8.

102.Lea R, Colson N, Quinlan S, et al. The effects of vitamin supplementation and MTHFR (C677T) genotype on homocysteine-lowering and migraine disability. Pharmacogenet Genomics 2009;19:422-8.

103. Schrader H, Stovner LJ, Helde G, et al. Prophylactic treatment of migraine with angiotensin converting enzyme inhibitor randomised, placebo controlled, crossover study. BMJ 2001;322:19-22. 